\title{
INSTRUMENTOS LEGAIS PODEM CONTRIBUIR PARA A RESTAURAÇÃO DE FLORESTAS TROPICAIS BIODIVERSAS ${ }^{1}$
}

Pedro Henrique S. Brancalion², Ricardo Ribeiro Rodrigues ${ }^{3}$, Sergius Gandolfi ${ }^{3}$, Paulo Yoshio Kageyama ${ }^{3}$, André Gustavo Nave ${ }^{3}$, Flávio Bertin Gandara ${ }^{3}$, Luiz Mauro Barbosa ${ }^{4}$ e Marcelo Tabarelli ${ }^{5}$

\begin{abstract}
RESUMO - O insucesso da maioria das iniciativas de restauração de florestas naturalmente biodiversas como a Mata Atlântica desencadeou um movimento intenso de discussão sobre a ciência e prática da restauração ecológica no Estado de São Paulo. Isso convergiu na construção participativa de uma resolução estadual de caráter técnico e orientador para restauração, a qual tem sido revisada e atualizada periodicamente em workshops que reúnem mais de 200 profissionais em cada evento. Essa resolução objetivou potencializar o estabelecimento de florestas biologicamente viáveis e com riqueza de espécies vegetais condizente com a dos ecossistemas de referência, a fim de garantir a persistência das florestas restauradas e proteger a biodiversidade nativa. As contribuições dessa resolução para o aperfeiçoamento e estímulo das ações de restauração são hoje evidentes. Entre 2003 e 2008, período de discussão dessa resolução, a produção de mudas de espécies arbustivas e arbóreas nativas no Estado cresceu de 13.000.000 (55 viveiros) para 33.000.000 (114 viveiros) por ano, e o número médio de espécies produzidas nos viveiros também aumentou de 30 para mais de 80 , refletindo o crescimento das ações de restauração. Do ponto de vista deste estudo, esse instrumento legal tem servido como mecanismo legítimo de política pública ambiental e de proteção dos interesses coletivos da sociedade. Particularmente, ele guia e orienta a maior parte dos investimentos em restauração ecológica e aumenta as perspectivas de maximização dos benefícios para a sociedade, que podem e devem ser obtidos com a restauração, incluindo a persistência da biodiversidade nas paisagens antrópicas tropicais.
\end{abstract}

Palavras-chave: Resolução SMA-08, Ecossistema de referência e Política pública ambiental.

\section{LEGAL INSTRUMENTS CAN ENHANCE HIGH-DIVERSITY TROPICAL FOREST RESTORATION}

\begin{abstract}
The failure of most efforts undertaken to restore natural high-diversity tropical forests, like the Atlantic Forest, has resulted in a very intense round of discussions on the science and best-practice of ecological restoration in the state of São Paulo, southeastern Brazil. This culminated in the participatory elaboration of a state resolution concerning technical and orientation aspects for restoration activities, which has been reviewed and updated periodically in workshops that bring together more than 200 professionals. The aim of this resolution was to maximize the establishment of biologically viable forests, with plant richness consistent with the reference ecosystem, to ensure the persistence of restored forests and protect native biodiversity. The contributions of this resolution for the improvement and stimulation of restoration actions are evident today. Between 2003 and 2008, when the resolution was heavily discussed, seedling production of native shrubs and trees in the state increased from 13,000,000 (55 nurseries) to 33,000,000 (114 nurseries) per year, and average number of plant species produced in nurseries also increased from 30 to over 80 , reflecting the increase of restoration actions. In our view, the existing legal instrument has served well as a mechanism to accompany environmental public policy aimed at protection of the collective interests of society. In particular, it guides and orients the bulk of investments in ecological restoration and enhances the prospects for maximizing the societal benefits that can and should be obtained from restoration activities, including the persistence of biodiversity in human-modified tropical landscapes.
\end{abstract}

keywords: Resolution SMA-08, Reference ecosystem and Environmental public policy.

\footnotetext{
${ }^{1}$ Recebido em 12.12.2009 e aceito para publicação em 02.03.2010.

${ }^{2}$ Universidade Federal de São Carlos, Centro de Ciências Agrárias, Araras-SP, Brasil. E-mail: <pedrohsb@yahoo.com.br>.

${ }^{3}$ Universidade de São Paulo, Escola Superior de Agricultura Luiz de Queiroz, Piracicaba, SP.

${ }^{4}$ Instituto de Botânica de São Paulo, São Paulo, SP.

${ }^{5}$ Universidade Federal de Pernambuco, Departamento de Botânica, Recife, PE.
} 


\section{INTRODUÇÃO}

O objetivo central da restauração florestal é o restabelecimento de florestas que sejam capazes de se autoperpetuar, ou seja, florestas biologicamente viáveis e que não dependam de intervenções humanas constantes. De forma geral, as iniciativas de restauração de florestas tropicais visam ao comprimento da legislação ambiental, ao restabelecimento de serviços ecossistêmicos elou a proteção de espécies nativas locais. Essas demandas, predominantemente de ordem local, somam-se, agora, a outra que opera nas escalas de paisagem, para potencializar os serviços de conservação da biodiversidade prestados pelas paisagens muito antropizadas (TABARELLI et al., 2010). Nesse contexto, a diversidade biológica não é apenas variável-chave para a obtenção de florestas viáveis e que são naturalmente ricas em espécies (i.e. florestas biodiversas), mas representa, também, alvo importante das próprias ações de restauração. Além disso, a adequação ambiental de setores produtivos, possível através da restauração, em muitos casos representa ganho de mercado e maior geração de emprego e renda, que dá dimensão econômica direta importante para as práticas de restauração.

Restauração ecológica é uma prática que ainda necessita de muitos avanços para que atinja a efetividade necessária, especialmente em regiões de ocorrência de florestas tropicais e subtropicais biodiversas, cujos remanescentes estão totalmente inseridos em paisagens fragmentadas e degradadas (i.e. as paisagens antrópicas). Justamente nessas condições mais críticas, a restauração ecológica tem de ser muito mais do que a aplicação de um simples pacote de técnicas silviculturais, acreditando-se que a diversidade biológica e os processos ecológicos serão restabelecidos por si só, em situações que já ultrapassaram o nível crítico da resiliência. Nesse contexto, a restauração ecológica deve assumir a difícil responsabilidade de restabelecer os processos ecológicos necessários ao estabelecimento de florestas viáveis, para que estas prestem os serviços almejados, sejam serviços ambientais, de conservação de biodiversidade, ou de fornecimento de produtos florestais, salvaguardando, assim, os interesses maiores da sociedade, a qual paga por esse tipo de investimento na formas de iniciativas públicas e privadas.

No Brasil, a limitação de conhecimentos aplicados e específicos de restauração ecológica de florestas tropicais, a escassez de profissionais com capacitação nesse tema e a intensa demanda por ações emergenciais de restauração resultaram, nas últimas décadas, em uma infinidade de iniciativas mal sucedidas e de pouca efetividade (BARBOSA et al., 2003; SOUZAe BATISTA, 2004; RODRIGUES et al., 2009a). Embora tais iniciativas tenham trazido inúmeros prejuízos econômicos e até mesmo ecológicos, em função, por exemplo, da adoção de espécies de plantas exóticas e invasoras, eles também apontaram caminhos a serem seguidos para que as ações de restauração ecológica atingissem um nível aceitável de efetividade, seja nos estabelecimento de florestas viáveis, seja na obtenção dos serviços ambientais esperados. Além das observações oriundas dessas experiências empíricas, os experimentos realizados por instituições de pesquisa nesse período passaram, também, por diferentes fases, inúmeras discussões e muitas polêmicas, o que é previsível e recomendado no âmbito de pesquisas de caráter aplicado e tecnológico, como a restauração florestal. Diversos encontros, reuniões e simpósios ocorreram nos últimos 20 anos no Brasil, colocando em dúvida a aplicação de vários conceitos no contexto da restauração florestal. Duas dúzias de eventos (e.g. cursos, simpósios, encontros e workshops) coordenados pelo Instituto de Botânica de São Paulo e com mais de 5.000 pessoas foram realizados entre 2000 e 2009 sobre a temática da restauração ecológica. Dentro desse contexto democrático de construção e organização do conhecimento e geração de tecnologia por pesquisadores, agentes públicos e profissionais, foi elaborada uma resolução estadual orientadora ou norteadora para a restauração ecológica, alicerçada no conhecimento empírico e científico existente até o momento sobre a restauração florestal no Brasil e no exterior (i.e. SMA-08 - disponível em: www.cetesb.sp.gov.br/licenciamentoo/legislacao/ estadual/resolucoes/2007_Res_SMA_8.pdf). Portanto, esse avanço da legislação no Estado de São Paulo foi fruto de pesquisa, discussão ampla, aplicação prática do conhecimento e revisão permanente dos erros e acertos. Desde sua primeira versão em 2001, essa resolução tem sido periodicamente revisada e atualizada em workshops que reúnem mais de 200 profissionais em média, os quais aprimoram o conteúdo da resolução com base nos avanços científicos e experiências pessoais. Destaca-se na resolução atual, a demanda por um mínimo de 80 espécies nativas regionais ao final do processo de restauração de florestas naturalmente biodiversas. 
Os impactos positivos dessa resolução para a evolução da restauração ecológica no Estado de São Paulo podem ser avaliados com base na riqueza de espécies florestais nativas e no número de mudas produzidas destas espécies após a publicação da primeira versão da resolução em 2001, o que retrata fielmente o enorme incremento no número de ações de restauração no Estado, onde em 2001, por exemplo, foram produzidas cerca de 13.000.000 mudas de espécies florestais nativas em 55 viveiros florestais. Embora o conjunto de viveiros produzisse ou já tivesse produzido 277 espécies ao todo, cada viveiro individualmente produzia, em média, menos de 30 espécies nessa época (BARBOSA et al., 2003). Já o diagnóstico de 2008 revelou a produção de 33.000.000 mudas de espécies florestais nativas por ano em 114 viveiros florestais, os quais produziam no conjunto 582 espécies e individualmente mais de 80 espécies (BARBOSA et al., 2009). Esses resultados positivos tornaram a resolução um modelo de instrumento legal a ser copiado por outros estados brasileiros, os quais se amparam na experiência e histórico da prática de restauração ecológica no Estado de São Paulo para a formulação de suas próprias políticas públicas estaduais sobre o tema, também buscando corrigir as deficiências já observadas na restauração nos respectivos estados.

O conteúdo da resolução paulista, principalmente seu foco na riqueza de espécies de plantas como base da restauração ecológica de florestas naturalmente biodiversas, é também um dos aspectos principais defendidos pelo Pacto pela Restauração da Mata Atlântica (www.pactomataatlantica.org.br), onde foi estabelecido o desafio coletivo de restauração de 15 milhões de hectares até 2050. O Pacto é composto hoje por 135 membros, sendo 85 representantes de ONGs e colegiados, 28 de órgãos governamentais, 16 da iniciativa privada e 6 de instituições de pesquisa, demonstrando que o referencial teórico da resolução é amplamente aceito pelos principais atores da restauração da Mata Atlântica, que é o bioma mais ameaçado do Brasil e uma das florestas tropicais mais ameaçadas do mundo (RODRIGUES et al., 2009a). No contexto da MataAtlântica e da conservação de sua biodiversidade, as florestas restauradas devem ser vistas como elemento capaz de ampliar a probabilidade de persistência das espécies nativas nas paisagens antrópicas, proporcionando a reintrodução (via mudas ou sementes) de espécies de plantas já extintas local ou regionalmente, oferecendo novas áreas de habitat florestal rico em espécies, aumentando a conectividade estrutural e funcional da paisagem, reduzindo os efeitos de borda ao redor de unidades de conservação e restabelecendo fluxos ecossistêmicos. Ou seja, a restauração ecológica é uma ferramenta-chave no planejamento e implementação de ações de conservação da biodiversidade (TABARELLI et al., 2010).

Diante do potencial da restauração ecológica como instrumento de conservação da biodiversidade e de adequação ambiental da atividade de produção agrícola, mas também como ferramenta para a obtenção de florestas viáveis e fornecedoras de serviços ambientais, é necessária ampla discussão pública para que sejam apontadas as vantagens, limitações e oportunidades de melhoria das ações de restauração em paisagens antrópicas, como a elaboração de instrumentos legais orientadores dessa atividade. Assim, o debate científico em torno do conteúdo da resolução estadual paulista, que será utilizada de modelo para essa discussão, vai permitir uma oportunidade de grande valia para o avanço da restauração ecológica no estado de São Paulo, no Brasil e no mundo.

\section{Histórico da restauração ecológica no Estado de São Paulo e a demanda por um mecanismo legal orientador dessa atividade}

O Brasil apresenta legislação ambiental com características únicas no mundo, estabelecidas em 1965 pelo Código Florestal. Por meio dessa lei, ficaram estabelecidas e regulamentadas as Áreas de Preservação Permanente (APPs), nas quais os esforços de restauração ecológica têm-se concentrado, a fim de atender à legislação e restabelecer os serviços ambientais realizados pelas florestas alocadas ao longo dos cursos d’água, principalmente. Embora o uso econômico das APPs seja vedado desde 1965, pois estas devem servir exclusivamente para a conservação da biodiversidade e manutenção dos serviços ambientais, a maioria delas ainda continua sendo muito utilizada para atividades de produção. No entanto, a restauração ecológica dessas áreas só é obrigatória quando for aplicada uma penalidade legal pelo seu uso indevido. Nessas situações, é legítimo que o estado estabeleça parâmetros mínimos que deverão ser seguidos no processo de regularização ambiental, os quais podem ser definidos, por exemplo, por meio de uma resolução estadual. Inclusive, o cumprimento integral das disposições contidas na resolução só será exigido (ver artigo $4^{\circ}$ ) nos casos de requisitos de licenciamento ambiental, de cumprimento de termos 
de ajustamento de conduta ou de reparação de danos ambientais, objetos de autuações administrativas e projetos implantados com recursos públicos. Assim, essa é uma forma legítima de o Estado exigir um mínimo de qualidade na mitigação, ou reparação de danos ambientais, que afetam a sociedade diretamente. No entanto, vale destacar que nos casos de restauração voluntária dessas áreas essa resolução tem importante papel orientador, buscando garantir a efetividade e a viabilidade dessas ações. A exemplo da resolução paulista, o Código Florestal constitui, também, um bom exemplo de instrumento legal que visa garantir a prestação de serviços ambientais pelos ecossistemas, bem como a conservação da biodiversidade que lhes é inerente (METZGER, 2010).

A ação mais efetiva dos órgãos públicos fiscalizadores e licenciadores nos últimos 20 anos com relação ao uso irregular dessas APPs, somada à maior exigência de certificação ambiental de produtos agrícolas e florestais (FSC, ISO 14001, Selo Verde, Etanol Verde, Boi Verde, Rainforest Alliance e selos orgânicos de forma geral) e a crescente preocupação da sociedade com questões ambientais, aumentaram consideravelmente a pressão por ações de restauração ecológica nessas áreas, impulsionadas primariamente pelo objetivo de proteção dos recursos hídricos.

No início do processo de regularização ambiental das APPs no Estado de São Paulo, a restauração era conduzida, principalmente, por meio do plantio de algumas espécies nativas e exóticas, algumas delas invasoras, mas sem combinação sucessional, o que elevava muito o tempo e os custos para a obtenção de uma vegetação de porte florestal ou a fisionomia florestal almejada. Buscando maior eficiência na produção de uma cobertura florestal em iniciativas de larga escala espacial, deu-se inicio a uma segunda fase da restauração no Estado, na qual se privilegiou o plantio de espécies nativas pioneiras (RODRIGUES et al., 2009a b). Nesse momento, a restauração passou a ser interpretada do ponto de vista mais ecológico, incorporando o conceito de sucessão florestal e privilegiando o uso de espécies da flora nativa brasileira, mas não necessariamente regionais. Na busca por iniciativas mais eficientes de restauração, tanto em termos de resultados quanto de custos, houve maior aproximação com os institutos de pesquisa e com as universidades, as quais fundamentaram suas recomendações na ecologia das florestais tropicais e formações florestais brasileiras, criando novas estratégias de restauração com base, principalmente, no conceito de sucessão secundária (KAGEYAMA e GANDARA, 2004).

Para acelerar a obtenção de uma fisionomia florestal numa área degradada, privilegiou-se, muitas vezes, a realização de plantios com grande número de indivíduos de poucas espécies arbóreas pioneiras, mais com número bem menor de indivíduos das espécies dos estágios sucessionais finais ou tardios da sucessão (SOUZA e BATISTA, 2004). Apesar de em poucos anos (2 a 3 anos) esses plantios terem sido capazes de formar uma fisionomia florestal, essas florestas mostraram-se biologicamente inviáveis, pois entraram em declínio com menos de 20 anos de idade. Esse fato decorreu, em grande parte, devido ao ciclo de vida curto da maioria dos indivíduos plantados, da mortalidade sincrônica das árvores do dossel, do baixo número de indivíduos de espécies mais longevas e da chegada insatisfatória de sementes de espécies típicas da floresta madura ou de seus estágios sucessionais mais tardios, por conta da degradação da paisagem regional (BRANCALION et al., 2009a). A senescência dos indivíduos pioneiros permitiu a reinvasão dessas áreas por gramíneas exóticas agressivas, as quais já estavam presentes na área antes do plantio das plantas nativas. Na verdade, as gramíneas se mantiveram no banco de sementes e de plântulas durante todo o período de persistência da floresta restaurada, por meio da entrada de luz pela borda e pelo dossel aberto por árvores decíduas na estação seca.

Em síntese, o simples plantio de uma população pioneira, com baixa riqueza e elevada dominância, embora capaz de sombrear rapidamente o solo e inibir temporariamente as gramíneas, mostrou-se insuficiente para desencadear o processo de sucessão secundária, o qual, via substituição direcional de vários grupos, deveria originar uma floresta biologicamente viável. Esse padrão emergiu, principalmente, em paisagens com longo histórico de degradação e resiliência severamente comprometida pela ausência de produção\movimentação de sementes de espécies de florestas maduras. Infelizmente, esse tipo de paisagem já predomina em várias regiões tropicais, a exemplo da Floresta Atlântica brasileira (TABARELLI et al., 2008).

Os insucessos resultantes dessa abordagem ou estratégia baseada em riqueza e diversidade de espécies reduzida (i.e. baixa diversidade) trouxeram significativos prejuízos econômicos, já que a maioria dessas iniciativas 
teve que ser refeita uma ou mais vezes para se efetivar. Considerando os 15 milhões de ha potenciais para a restauração ecológica no domínio da Mata Atlântica do Brasil no âmbito do Pacto pela Restauração da MataAtlântica (http://www.pactomataatlantica.org.br) e que a implantação e manutenção por dois anos de reflorestamentos com espécies nativas (cerca de 1.700 indivíduos/ha) tem um custo variável entre R\$6.000,00 e R\$10.000,00/ha, conclui-se que é possivel desperdiçar bilhões de reais nesse processo caso não se adotem técnicas que permitam a restauração de florestas biologicamente viáveis ou autoperpetuáveis (BARBOSA et al., 2003). O grande montante de recursos a serem investidos na restauração ecológica pelas empresas, sociedade civil e governos só se justifica se essa atividade de fato trouxer os resultados esperados, de forma que um nível mínimo de qualidade deve ser exigido como mecanismo legítimo de proteção dos interesses coletivos envolvidos nessa atividade. Nesse sentido, os atores da restauração ecológica do Estado de São Paulo passaram a buscar mecanismos técnicos e legais que coibissem a reincidência desses erros do passado e possibilitassem maior efetividade ecológica e exequibilidade financeira das ações de restauração no futuro.

O Ponto mais controverso dessa Resolução: a orientação de ações que resultem, ao final do processo de restauração, numa diversidade florística compatível com o ecossistema de referência

Entre as diversas recomendações presentes nessa resolução, podem-se citar (1) a caracterização do solo, visando criar as condições adequadas para a restauração; (2) o diagnóstico prévio da área visando definir prioridades de restauração baseadas nas características da paisagem regional e particularizar as ações de restauração para cada situação da paisagem, em função da resiliência dessas áreas; (3) a explicitação de outras possíveis metodologias de restauração, que não apenas o plantio de mudas, como a nucleação, a condução da regeneração natural, a semeadura direta etc.; (4) a possibilidade do uso de sistemas agroflorestais, como metodologia de manutenção das áreas em processo de restauração; e (5) o uso de um mínimo de espécies atrativas da fauna e de espécies raras ou ameaçadas de extinção. Essas recomendações nada mais são do que o resultado do referencial teórico e da experiência prática da maioria dos profissionais envolvidos com a restauração ecológica no Estado. Entre tais orientações, destaca-se a recomendação para que sejam estabelecidas ações de restauração que garantam diversidade florística compatível com o ecossistema de referência nas áreas restauradas, incluindo nisso os conceitos de riqueza e de equabilidade. Essa recomendação é a que mais recebeu destaque na publicação dessa resolução, tendo provavelmente sido o principal gerador deste debate. Diante disso, torna-se necessário transcrever o conteúdo desse artigo (SÃO PAULO, 2007), para que não haja interpretações equivocadas: “em áreas de ocorrência das formações de Floresta Ombrófila, de Floresta Estacional Semidecidual e de Savana Florestada (cerradão), a recuperação florestal deverá atingir, no período previsto em projeto, o mínimo de 80 espécies florestais nativas de ocorrência regional”. Dessa forma, fica claro que esse nível de riqueza só será cobrado ao final do processo de restauração, que pode durar de poucos até dezenas de anos, dependendo do projeto, e apenas para florestas tropicais que naturalmente são de elevada riqueza. O questionamento dessa orientação da resolução causa estranheza, pois será que algum restaurador de regiões tropicais não pretende que suas áreas restauradas tenham elevada riqueza ao final do processo de restauração? Nesse sentido, mais uma reflexão merece destaque, pois se pode considerar o uso de uma espécie altamente invasora como Pinus elliottii como facilitadora da restauração, mesmo que em 11 anos apenas duas dezenas de espécies nativas regenerem em seu sub-bosque (MODNA et al., 2010)? Nota-se, também, que não é exigido qualquer número mínimo de espécies ao final do processo de restauração de formações florestais ou outros tipos de vegetação que não tenham a elevada riqueza como característica natural ou que sejam mais complexas de restaurar, dadas as limitações do meio físico, tal como florestas de restinga, florestas deciduais, florestas paludosas e manguezais (ver artigo $7^{\circ}$ da Resolução). Diante da importância dessa recomendação no contexto da Resolução, do ponto de vista de restauração e, consequentemente, deste estudo, justifica-se maior detalhamento do referencial teórico que embasou a ênfase dada à biodiversidade nessa Resolução e na restauração ecológica de forma geral.

\section{Como não incluir a biodiversidade como base para a restauração ecológica de Hotspots de alta diversidade?}

O Estado de São Paulo está incluído na área de abrangência dos biomas Cerrado e Mata Atlântica, os quais constituem, respectivamente, o segundo ( $\sim 2$ milhões de $\mathrm{km}^{2}$ ) e o terceiro ( 1,3 milhão de $\mathrm{km}^{2}$ )

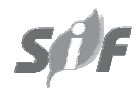

Revista Árvore, Viçosa-MG, v.34, n.3, p.455-470, 2010 
maiores biomas brasileiros (IBGE, 2006). A Mata Atlântica é um bioma único caracterizado por alta diversidade de espécies e altos níveis de endemismo, com riqueza de plantas estimada em 20.000 espécies, das quais 8.000 são endêmicas (MITTERMEIER et al., 2004). Da mesma forma, o Cerrado apresenta características de extraordinário valor para a conservação, com cerca de 10.000 espécies vegetais, das quais aproximadamente 4.400 também são endêmicas (MITTERMEIER et al., 2004). Apesar do inestimável valor biológico desses biomas, estes se encontram seriamente ameaçados. A cobertura natural da Mata Atlântica no Brasil foi reduzida para menos de $15 \%$ de sua área, e $80 \%$ dos remanescentes têm menos de 50 ha (RIBEIRO et al., 2009; TABARELLI et al., 2010), o que também ocorreu no Cerrado, que teve sua cobertura reduzida em mais de $70 \%$ (KLINK e MACHADO, 2005). Por essas características, Cerrado e Mata Atlântica foram identificados como "hotspots", ou seja, ecossistemas prioritários para a conservação da biodiversidade global (MYERS et al., 2000).

No Estado de São Paulo, essa situação é ainda mais crítica. Embora a Floresta Ombrófila Densa se encontre em melhor estado de conservação, com ainda 42\% de sua área remanescente, o mesmo não se observa com as demais formações florestais. Houve drástica redução da cobertura de Cerrado e de Floresta Estacional Semidecidual para $8,5 \%$ e $8,2 \%$, respectivamente (RODRIGUES e BONONI, 2008), justamente pelo fato dessas formações ocorrerem em ambiente de elevada aptidão agrícola. Além disso, os poucos remanescentes desses tipos vegetacionais têm sido historicamente degradados pela extração de madeira, caça, incêndios, invasão de gado e diversos impactos decorrentes da atividade agrícola do entorno e da altíssima fragmentação (TABARELLI et al., 2005; DURIGAN et al., 2007). Consequentemente, as paisagens que abrigam remanescentes desses ecossistemas demandam ações urgentes de restauração ecológica com o objetivo de garantir a persistência de florestas biologicamente viáveis, ampliando as chances de permanência da biodiversidade nativa e garantindo os serviços ambientais que tanto interessam à sociedade (TABARELLI et al., 2005, 2010). Em outras palavras, nas paisagens antrópicas as florestas restauradas podem realizar um serviço de conservação da biodiversidade complementar ao realizado pelas unidades de conservação e até ampliar o papel dessas áreas via expansão das conectividades estrutural e funcional da paisagem.

Revista Árvore, Viçosa-MG, v.34, n.3, p.455-470, 2010

Revista Árvore, Viçosa-MG, v.34, n.3, p.455-470, 2010

\section{Coerência das ações de restauração ao ecossistema de referência}

A escolha e caracterização do ecossistema de referência são fundamentais para orientar as ações de restauração ecológica (ARONSON et al., 1995; CLEWELL eARONSON, 2007). Combase no ecossistema de referência é que se definem alguns atributos necessários para que determinada área seja considerada como restaurada (SERI, 2004), entre os quais se destaca, para a restauração de florestas tropicais, a elevada diversidade de espécies vegetais. Para se ter uma ideia da riqueza encontrada nas três formações florestais para as quais se requerem no mínimo 80 espécies arbustivas e arbóreas ao final do processo de restauração, cabe observar os resultados obtidos nos levantamentos florísticos das espécies dessas formas de vida de três áreas de 10 ha inseridas em Unidades de Conservação do Estado de São Paulo pelo Projeto Parcelas Permanentes (BIOTA/FAPESP). Foram encontradas nas parcelas de Floresta Estacional Semidecidual, Cerradão e Floresta Ombrófila Densa, respectivamente, 148, 116 e 205 espécies com circunferência à altura do peito superior a $15 \mathrm{~cm}$ (PARCELAS PERMANENTES, 2006). Considerando a paisagem regional em levantamentos florísticos visando à escolha de espécies para a restauração ecológica em 21 projetos realizados no âmbito do Programa de Adequação Ambiental do LERF/ESALQ/USP, foram encontradas $238 \pm 65$ (média \pm desvio-padrão) espécies arbustivas e arbóreas nativas (RODRIGUES et al., 2010). Além da riqueza per se, boa parte dos padrões funcionais que caracterizam o ecossistema de referência, tal como a estrutura das comunidades, as interações ecológicas, a composição funcional e os processos biogeoquímicos, estão fortemente correlacionados com a riqueza de espécies presentes na floresta restaurada (JONES et al., 1994).

Florestas pobres em espécies, sejam elas naturais ou restauradas, apresentam baixa diversidade funcional e, dessa forma, são menos capazes de reter biodiversidade e prestar uma gama maior de serviços ambientais. É importante salientar que em muitos casos a restauração florestal leva ao estabelecimento de pequenos fragmentos de floresta, os quais, como fragmentos, tendem naturalmente a se estabilizar como sistemas sucessionais iniciais em paisagens extremamente fragmentadas (TABARELLI et al., 2008). 
Caso se tenha conhecimento científico consistente sobre processos envolvidos na reconstrução das florestas que permitissem identificar se existe e quem são as poucas espécies facilitadoras que promovessem, através da sucessão secundária, o acúmulo gradual e garantido da biodiversidade em diferentes condições de degradação, poderia ser revista a necessidade de um número mínimo de espécies a serem adotadas inicialmente em alguns casos. Enquanto isso não ocorre, a responsabilidade de cada um de nós é buscar o máximo de diversidade possível no processo de restauração para ampliar as chances de se estabelecerem florestas biologicamente viáveis e que auxiliam na manutenção da diversidade biológica nas paisagens antrópicas, como forma de evitar a erosão do patrimônio ou ativo biológico abrigado nos ecossistemas nativos.

Criação de microssítios heterogêneos de regeneração e favorecimento da sucessão secundária em paisagens muito fragmentadas

A grande diversidade de árvores do dossel e do estrato emergente das florestas tropicais exerce papel fundamental na criação e manutenção de microssítios particulares de regeneração, dadas as variações de altura, tamanho de copa, densidade de folhagem, épocas, intensidade (perenifólias, caducifólias e semicaducifólias) e duração do período de perda foliar (MONTGOMERY e CHAZDON, 2001; GANDOLFI et al., 2007). Além das variações de microclima resultantes dessas diferentes características das árvores do dossel (NICOTRA e CHAZDON, 1999), a riqueza de microssítios de regeneração é acentuada pelos efeitos da deposição e constituição da serapilheira nas plântulas (MOLOFSKY eAUGSPURGER, 1992; GUILLMAN e OGDEN, 2005), na germinação (VÁZQUEZ-YANEZ et al., 1990), na mineralização de nutrientes (ZINKE, 1962; MONTAGNINI e SANCHO,1990), na liberação de aleloquímicos (BORGES et al., 1993) e na interação com microrganismos (LAMBAIS et al., 2006; MITCHELL et al., 2010).

As diferentes espécies florestais, submetidas a esse ambiente temporal e espacialmente heterogêneo, não se distribuem nele de forma homogênea ou independente das variáveis ambientais. Ao contrário, essas especies se estabelecem devido a diferenças de tolerância às condições ambientais e têm a ocorrência selecionada em algum nível pela distribuição dessa heterogeneidade. Assim, qualquer floresta restaurada terá de formar com o tempo um dossel diversificado, a fim de criar as condições adequadas de microclima e de microssítio de regeneração para que diferentes espécies tolerantes à sombra, que são a maioria das espécies nas florestas tropicais e subtropicais, possam se estabelecer e regenerar no sub-bosque, além de outras formas de vida como as epífitas e as trepadeiras (SIQUEIRA-FILHOeTABARELLI, 2006; BRANCALION et al., 2009b). Dessa forma, a composição, riqueza, abundância e arranjo espacial das espécies do dossel irão afetar, em curto e longo prazos o grau de heterogeneidade ambiental existente no sub-bosque e do próprio dossel da floresta em restauração. Em paisagens muito fragmentadas, degradadas e com menor cobertura de vegetação nativa, o aporte de novas espécies de dossel e subdossel na área restaurada tende a ocorrer de forma lenta e pouco abundante, limitando a heterogeneidade desse estrato caso as espécies vegetais não sejam introduzidas na área via ações de restauração.

Utilizando inicialmente muitas espécies pioneiras e tardias de dossel e sub-dossel, dispostas num arranjo espacial favorável e com abundância adequada, pode-se conseguir a formação de um dossel predominantemente de pioneiras e ambiente florestal em apenas dois anos. Gradualmente nos primeiros 10 a 20 anos da restauração, a presença dessas pioneiras no dossel vai se reduzir, e elas serão aos poucos substituídas por espécies tolerantes à sombra e de estágios sucessionais mais avançados, aumentando gradualmente a heterogeneidade florística e arquitetural desse estrato. As estratégias de restauração ecológica devem, assim, garantir que espécies pioneiras, secundárias e clímax estejam presentes numa abundância e distribuição espacial adequadas, a fim de permitir que o dossel seja continuamente refeito através de um processo de substituição sucessional, o que aumenta as chances de que o processo de sucessão secundária ocorra localmente. Na floresta madura, esse estrato permanecerá como um mosaico em que as espécies pioneiras e secundárias estarão presentes, porém com menor abundância, predominando as espécies mais climácicas.

Outro fator de suma importância para aumentar a previsibilidade da sucessão secundária são o aporte de sementes nas áreas restauradas e o consequente desenvolvimento do sub-bosque, possibilitando a viabilidade e a persistência da floresta no tempo. Em condições de elevada fragmentação e degradação, a introdução de dezenas de espécies nativas na área restaurada pode assegurar a produção de sementes 
dos diferentes grupos ecológicos que compõem o dossel, subdossel e o estrato emergente no próprio local e, assim, possibilitar a regeneração e manter a heterogeneidade da floresta em formação durante a sucessão. Dossel florestal permanente e diversificado pode ser, também, fundamental para garantir o recrutamento contínuo de diferentes grupos ecológicos de plantas, os quais atingem a floresta restaurada via movimentação lenta de sementes na paisagem (MELO et al., 2006).

\section{Recursos para polinizadores e dispersores}

Um dos principais resultados do processo evolutivo nas florestas tropicais e subtropicais é a coexistência de grande número de espécies vegetais. Juntamente com essas espécies, também evoluíram as espécies polinizadoras e dispersoras de sementes (KEARNS et al., 1998; BASCOMPTE et al., 2006). Como a maioria das espécies de florestas tropicais é alógama (BAWA, 1974; CASTRO, 2007) e tem suas sementes dispersas por animais (SEIDLER e PLOTKIN, 2006; ALMEIDANETO et al., 2008), a presença de polinizadores e dispersores de sementes é requisito para a viabilidade biológica das florestas restauradas e consequentemente para sua perpetuação no tempo. Caso a oferta de recursos a esses organismos seja escassa, pouco diversificada ou restrita a certos períodos do ano, a abundância e diversidade de agentes polinizadores e dispersores serão também restritas, o que certamente pode comprometer a perpetuação das florestas restauradas e o papel delas na conservação da biodiversidade regional (SILVA, 2003). Dessa forma, em situações em que o aporte de sementes oriundas de fragmentos florestais remanescentes do entorno seja limitado (BERTONCINI e RODRIGUES, 2008), o uso de métodos que garantam a presença de elevada diversidade de espécies nativas regionais favorece a criação de uma rede de interações mais complexa e contribui, assim, para a reconstrução de uma floresta funcional e perpetuável. Uma vez que cada espécie em particular iniciará a produção de flores e frutos em diferentes momentos, a presença de um grande número de espécies de plantas amplia a base de recursos naturais para os organismos consumidores durante o processo de sucessão, atraindo e mantendo populações de polinizadores, dispersores, herbívoros e organismos dependentes. Ou seja, a estruturação trófica da floresta restaurada dependerá, em grande parte, da riqueza de estratégias biológicas incorporadas ao plantio inicial. Além de favorecer a perpetuação das espécies introduzidas ou regeneradas na própria área restaurada, a oferta regular e diversificada de recursos alimentares para animais frugívoros favorece, também, a chegada de sementes oriundas de fragmentos do entorno através da atração de maior diversidade e quantidade de animais dispersores (SILVA, 2003; JORDANO et al., 2006).

\section{Favorecimento de outras formas de vida vegetal, de insetos e de microrganismos}

Almejar elevada diversidade de espécies arbustivas e arbóreas nativas nas áreas em processo de restauração de paisagens fragmentadas não significa que se está restaurando uma floresta pobre em formas de vida e estratégias biológicas vegetais. No caso das lianas e epífitas, dois grupos de grande importância para a manutenção da dinâmica de florestas tropicais, a ocorrência e distribuição dessas espécies na floresta não se dão de forma aleatória, pois há preferências específicas por árvores com determinadas características de tronco e estrutura (ZIMMERMAN e OLMSTED, 1992; MUÑOZ et al., 2003). Assim, se quisermos que as comunidades de epífitas e lianas sejam restabelecidas nas áreas restauradas a médio e longo prazos, seja através de reintrodução das espécies ou da recolonização natural, é preciso proporcionar diversidade de troncos e de estruturas de copas, o que só é possível com a efetivação de uma grande diversidade de arbustos e árvores (BELLOTTO et al., 2009). Microrganismos até então desconhecidos pela ciência também demonstraram ter estreita relação com a diversidade de árvores (LAMBAIS et al., 2006), evidenciando claramente que a diversidade de microrganismos numa comunidade florestal deve estar diretamente relacionada com a diversidade vegetal (MITCHELL et al., 2010). Não se deve ignorar ainda a frequente especificidade de insetos fitófagos em relação às espécies vegetais (DYER et al., 2007), ressaltando-se novamente que uma floresta complexa e funcional só poderá ser obtida caso elevada diversidade de espécies vegetais regionais esteja presente na área restaurada.

\section{Aumento da conectividade da paisagem}

No contexto da conservação da biodiversidade, um dos principais benefícios atribuídos à restauração ecológica tem sido o aumento da conectividade da paisagem, o que reduz as chances de extinções locais em função de minimizar restrições à migração, reduzir a vulnerabilidade a eventos estocásticos de flutuação 
populacional e evitar problemas genéticos decorrentes do restrito fluxo gênico (METZGER, 2003). Esse benefício é ainda maior em paisagens antrópicas, onde os poucos, pequenos e muito degradados remanescentes de florestas naturais estão separados por grandes distâncias (METZGER, 2009). Essa maior interação ecológica das áreas restauradas com os remanescentes de vegetação nativa contribui significativamente para que se restabeleçam as redes complexas de interações que garantem o funcionamento das florestas, naturais ou restauradas, e favoreçam a sobrevivência tanto das espécies vegetais como também dos animais, insetos e microrganismos que dependem dessas plantas (TABARELLI et al., 2005). Particularmente no caso da restauração de APPs localizadas na condição ribeirinha, essas iniciativas resultam na reconstrução de excelentes corredores ecológicos, interligando remanescentes florestais antes isolados na paisagem regional. Contudo, dependendo da metodologia usada para a restauração dessas áreas, elas poderão aumentar apenas a conectividade estrutural, mas não a funcional. Para que um corredor ecológico seja funcional, favorecendo consequentemente o fluxo de organismos, sementes e grãos de pólen - que somados constituem o fluxo gênico -, o contraste entre a vegetação do corredor e a do fragmento deve ser minimizado, de forma que esse corredor possua características florísticas e fisionômicas as mais próximas possíveis dos habitats presentes em suas extremidades (METZGER, 2003; TABARELLI et al., 2010). Nesse contexto, a presença de elevada diversidade de espécies nativas nas áreas em processo de restauração, que em paisagens muito fragmentadas é obtida quase sempre por meio da introdução direta dessas espécies na área através de ações diversas de restauração ecológica, pode, em muito, contribuir para o aumento da conectividade funcional da paisagem e para a conservação da biodiversidade na escala regional (RODRIGUES et al., 2009b).

\section{Resgate de espécies vegetais vulneráveis e ameaçadas de extinção}

Muitas vezes, argumenta-se que a conservação de espécies raras e ameaçadas não deva ser alvo da restauração ecológica, mas sim de programas específicos para essa finalidade. Contudo, em situações muito dramáticas para a conservação da biodiversidade, como a dos Hotspots, verifica-se que o número de espécies vulneráveis e ameaçadas de extinção é tão grande que estratégias pontuais têm poucas chances de serem bem-sucedidas, já que o habitat dessas espécies foi drasticamente reduzido e a própria paisagem não favorece os fluxos necessários para minimizar os riscos de extinção local (BECKER et al., 2009). Nessas situações, as estratégias de conservação da biodiversidade devem, inclusive, se estender para além dos limites das áreas protegidas, trabalhando de forma mais integrada com a paisagem do entorno para se obter maior efetividade das ações (TABARELLI et al., 2005; CHAZDON et al., 2009), como é o caso dos corredores de biodiversidade.

Nesse contexto, a restauração ecológica de florestas tropicais surge como uma das principais alternativas para o resgate e manutenção de espécies ameaçadas de extinção, pois permite o restabelecimento do habitat dessas espécies, a reintrodução de suas populações na paisagem regional e contribuem para a conservação e reconexão de fragmentos florestais degradados que possam conter essas espécies (TABARELLI et al., 2005; RODRIGUES et al., 2009b). Contudo, a restauração ecológica só cumprirá essa missão se houver compromisso dos restauradores com ela, levando para além das fronteiras das unidades de conservação a preocupação com a restauração e conservação da diversidade biológica. Caso não sejam adotadas medidas que incentivem o resgate dessa elevada diversidade de espécies nativas regionais, principalmente aquelas ameaçadas de extinção, por meio da restauração ecológica, dificilmente essas espécies serão incorporadas à área restaurada. Isso porque as espécies ameaçadas já foram, em sua maioria, extintas localmente ou tiveram suas populações muito reduzidas nas paisagens antrópicas, tendo, assim, chances mínimas de colonizar as áreas restauradas caso não tenham sido ali reintroduzidas propositalmente pelas ações de restauração, tal como observado em árvores com grandes sementes dispersas por vertebrados na Mata Atlântica (SILVA e TABARELLI, 2000). Essa preocupação tem mudado, inclusive, o entendimento do papel das áreas protegidas no Estado de São Paulo, que criou uma Resolução estadual específica para possibilitar a coleta de sementes em Unidades de Conservação (SÃO PAULO, 2008a), visando ao acesso a espécies vegetais vulneráveis e ameaçadas de extinção, por meio do plantio de mudas ou da semeadura nos remanescentes naturais e nas áreas em processo de restauração. Essa preocupação está explícita no artigo $6^{\circ}$ da Resolução.

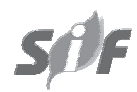

Revista Árvore, Viçosa-MG, v.34, n.3, p.455-470, 2010 


\section{Os problemas associados à Resolução são quase sempre o resultado de sua interpretação e aplicação Equivocadas}

A maioria das críticas normalmente feitas à Resolução paulista é reflexo de equívocos em sua interpretação e aplicação, principalmente dessa versão mais atual de 2007, que tentou corrigir a maioria das incoerências identificadas nas versões anteriores. Logicamente, a restauração ecológica e por consequência a própria resolução têm ainda muito a evoluir para garantir a restauração de florestas biodiversas autoperpetuáveis, incorporando conceitos de grupos funcionais, de diversidade genética, de incorporação de outras formas de vida, de mudanças climáticas, de processos biogeoquímicos etc. (RODRIGUES et al., 2009a). Contudo, é evidente que para o atual estado da arte da restauração ecológica essa resolução orientativa tem contribuído significativamente para o ganho de qualidade das ações de restauração, conforme descrito anteriormente. Visando contra-argumentar as principais críticas feitas à Resolução SMA-08, nos tópicos subsequentes são apresentadas as contestações dessas críticas com base no referencial conceitual da restauração e na própria aplicação prática da Resolução, atentando para a relação custo-benefício das ações de restauração, já que se trata de uma resolução de caráter orientador.

As recomendações da resolução não estão respaldadas pela ciência: A grande carência de conhecimentos científicos sobre a restauração ecológica de florestas tropicais é um desafio a ser enfrentado. Cerca de $80 \%$ da pesquisa em restauração ecológica publicada em periódicos internacionais tem sido conduzida em países desenvolvidos (ARONSON et al., 2010), embora 26 dos 34 Hotspots estejam inseridos em países tropicais em desenvolvimento (MYERS et al., 2000), onde as pesquisas nessa área seriam mais necessárias. Tal descompasso entre a pesquisa e a urgente demanda de ações de conservação e restauração nos países em desenvolvimento sinaliza que não há tempo a perder e que políticas públicas devem ser construídas em prol da biodiversidade e de seus valores, mesmo considerando a grande carência de informações, adotando-se o princípio da precaução. Por exemplo, a fundamentação científica do Código Florestal também tem sido constantemente questionada, mas, quando se faz uma análise detalhada das suas recomendações com base na própria ciência, verifica-se que seria necessário maior rigor ainda no estabelecimento de parâmetros (METZGER, 2010). Nesse contexto, a ciência não pode atuar como barreira para o avanço das práticas e políticas públicas que visam potencializar os esforços de conservação e restauração da biodiversidade remanescente, mas sim como ferramenta de aperfeiçoamento constante e direcionadora de novos rumos, tal como trabalhado nos constantes encontros de aperfeiçoamento e revisão da Resolução. Apesar dessa carência de informações, vários dos trabalhos até então publicados de ecologia, biologia da conservação e de restauração ecológica têm destacado direta ou indiretamente o papel da biodiversidade para a sustentação das ações de restauração de ecossistemas naturais de alta diversidade (as referências utilizadas neste artigo são um exemplo disso), justificando sua defesa inequívoca diante de uma postura menos comprometida com o papel central que a biodiversidade deve ocupar na restauração ecológica.

80 espécies é um número arbitrário, sem significado ecológico: Se respeitarem inteiramente as informações dos ecossistemas de referência para determinar o número de espécies da restauração ecológica, a conclusão será de que 80 espécies representam um número reduzido se o foco é a restauração de florestas naturalmente biodiversas. Esse patamar mínimo de 80 espécies a ser atingido no final do processo de restauração foi definido pelos profissionais da restauração ecológica do Estado de São Paulo, durante vários workshops de discussão, como uma meta que poderia ser alcançada pelos viveiros florestais e que também traria ganhos efetivos para a viabilidade biológica das áreas restauradas. O enriquecimento induzido dessas áreas poderia ser feito já na fase de plantio das mudas ou semeadura, ou ao longo de todo o processo de restauração, usando-se para isso ações efetivas de restauração que promovessem esse enriquecimento, como a atração de dispersores com poleiros naturais ou artificiais, adição do banco de sementes de áreas naturais etc. Caso essas ações não resultassem num incremento efetivo de espécies em prazo aceitável, ações diretas de enriquecimento deveriam ser adotadas. Sem a adoção de um critério mínimo de riqueza de espécies, estamos informando à sociedade que é possível restaurar florestas biodiversas usando qualquer quantidade de espécies vegetais. Oitenta espécies representam muito menos da metade da riqueza de espécies arbustivas e arbóreas convivendo em um único hectare de florestas tropicais e subtropicais, e como em qualquer mecanismo legal, 
alguns valores de referência devem ser claramente definidos, pois qualquer possibilidade de interpretação subjetiva de uma norma dificulta ou, mesmo, impede sua aplicação por parte dos agentes públicos. Esse número adotado deverá sempre ser revisto, e até mesmo ampliado, com a confirmação de sucesso da aplicação da Resolução na restauração de áreas. Contudo, independentemente do número em si adotado pela resolução para propor a restauração de florestas com maior diversidade, a inserção de valores mínimos de diversidade vegetal a ser atingida na restauração ecológica está amparada cientificamente como forma de sustentar os processos ecológicos e o funcionamento dos ecossistemas (GRIME, 1997; LOREAU et al., 2001; REY BENAYAS et al., 2009; WRIGHT et al., 2009).

- A Resolução coibiu as iniciativas de restauração ecológica: Esse fato, ou tendência, não se confirmou nos últimos anos, já que na prática foi o período em que mais houve incremento das iniciativas de restauração no Estado de São Paulo e no Brasil, acompanhando a tendência mundial. Vale ainda destacar que cada vez mais essas iniciativas estão em consonância com o preconizado na Resolução estadual, apesar de ela ser apenas orientadora das iniciativas de restauração. Isso é facilmente observado pelo crescimento no número de empresas e instituições que implantam projetos de restauração ecológica, que produzem sementes e mudas e que trabalham na captação de recursos para essas atividades.

- O cumprimento da Resolução encarece a restauração ecológica: A Resolução não estabelece que a única metodologia de restauração é o plantio de mudas, o que poderia, sim, aumentar o custo da restauração. Ao contrário, foi a primeira vez que se estabeleceram instrumentos legais possibilitando o uso de outras técnicas de restauração, a exemplo da condução da regeneração natural, nucleação, semeadura direta etc. É verdade que, nas paisagens muito degradadas e fragmentadas, onde o plantio de mudas ou sementes é indicado como prática necessária de restauração, um dos principais fatores que favorecem atualmente o uso de elevada diversidade florística de espécies nativas é justamente a ausência de diferença de preço na implantação de reflorestamentos com alta ou baixa diversidade de espécies. O custo da muda não varia entre as espécies em todos os viveiros florestais do Estado (cerca de R\$0,65, em tubetes de $56 \mathrm{~cm}^{3}$ ) e também não varia com o número de espécies solicitado.
A adoção de um valor padrão para todas as espécies se baseia no fato de que a contribuição do valor da semente no custo total da muda, que é o principal insumo para se obter a diversidade, é pouco significativa. A maior parte dos custos da muda se refere aos demais insumos, à infraestrutura e à mão de obra. Como também não há diferença no custo de implantação do reflorestamento em função do número ou da composição de espécies utilizadas, chega-se facilmente à conclusão de que não há justificativa econômica para não utilizar elevada diversidade florística na restauração ecológica nem a de que a Resolução encareça os projetos.

- Os profissionais dos órgãos públicos responsáveis pela elaboração de projetos, licenciamento e fiscalização ambientais não detêm conhecimento para aplicar a Resolução: Esse argumento apenas reforça a necessidade de capacitação e atualização constante desses técnicos em restauração ecológica, o que é estimulado no próprio artigo $13^{\circ}$ da resolução, não constituindo, portanto, em uma deficiência dessa Resolução. Por ter caráter orientador, baseando-se em princípios de diagnóstico ambiental, de escolha de métodos diferenciados de restauração para cada situação do diagnóstico e de estabelecimento de alguns parâmetros indicadores do sucesso da restauração, a Resolução acaba por auxiliar o trabalho desses técnicos. Diante da crescente demanda e execução de projetos de restauração ecológica, é essencial que o poder público crie estrutura adequada, de corpo técnico e infraestrutura, para orientar e fiscalizar as ações de restauração ecológica, exercendo as funções que lhe competem.

A adoção das recomendações da Resolução, com a adequação da escolha das espécies, das abundâncias e do arranjo espacial, aumenta a previsibilidade de sucesso na formação e manutenção de uma fisionomia e habitat florestal que se sustentem pelo menos em médio prazo (viabilidade biológica), mesmo que por longo tempo não haja o aporte de novas espécies na área em restauração. O estímulo via resolução dessa maior previsibilidade pode, de maneira prática, minimizar a necessidade de frequente fiscalização, bem como reduzir os casos de insucesso.

A Resolução dificulta a restauração em pequenas propriedades: Para facilitar a aplicação da resolução em pequenas propriedades, foi estabelecido que “a recuperação florestal na pequena propriedade rural poderá ser assistida pelo poder público,

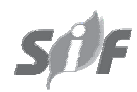

Revista Árvore, Viçosa-MG, v.34, n.3, p.455-470, 2010 
dispensando-se a apresentação de projeto técnico...”. Além disso, buscou-se estimular a restauração ecológica nessas pequenas propriedades deixando expressa a possibilidade de plantio consorciado de espécies nativas com espécies agrícolas, por até três anos, como forma de manutenção do reflorestamento. Além disso, há uma Medida Provisória Federal (nº 2166-67 de 2001) e também uma Resolução estadual paulista (SÃO PAULO, 2008b) que permite o uso de sistemas agroflorestais em APPs de propriedades familiares, onde essas áreas desempenham importante papel social direto, possibilitando a conciliação de objetivos conservacionistas e produtivos nessas situações. A Resolução estadual fornece esse respaldo, não gerando, portanto, conflito.

- A Resolução estimula o uso de espécies exóticas e não regionais para que se atinja numericamente as 80 espécies requeridas: A Resolução é bem clara na descrição desse tema “... a recuperação florestal deverá atingir, no período previsto em projeto, o mínimo de 80 espécies florestais nativas de ocorrência regional”. Dessa forma, um projeto com 60 espécies nativas regionais e outras 20 exóticas ou não regionais não cumpre a Resolução. Como as espécies exóticas são usadas na restauração ecológica há muito mais tempo do que a própria existência da Resolução, não é correto estabelecer esse vínculo causal. Cabe ressaltar também que um dos principais motivadores da construção dessa Resolução foi o uso abusivo de espécies exóticas nos projetos de restauração ecológica, incluindo invasoras, antes ignoradas pelos órgãos fiscalizadores e hoje definidas como tal na Resolução estadual, que cumpre novamente com seu papel orientativo no processo de efetivação da restauração ecológica como prática. Há, inclusive, a recomendação de controle inicial de espécies exóticas em seu artigo $9^{\circ}$, evidenciando a preocupação com as invasões biológicas no âmbito da restauração ecológica.

- A Resolução restringe o uso de outros métodos de restauração que não o plantio de mudas: Conforme já comentado, na Resolução fica clara a total liberdade para que o restaurador defina a metodologia ou conjunto de metodologias mais adequadas para a área em questão, baseando-se no diagnóstico prévio da resiliência da área, desde que essa ação de restauração resulte, ao final do tempo estipulado em projeto (que não é fixo e depende da recomendação do técnico que conduziu o trabalho), numa área restaurada com diversidade minimamente compatível com o ecossistema de referência. Isso fica claramente definido em seu artigo $5^{\circ}$ - "a recuperação florestal exige diversidade elevada, compatível com o tipo de vegetação nativa ocorrente no local, a qual poderá ser obtida através do plantio de mudas e, ou, de outras técnicas, como nucleação, semeadura direta, indução e, ou, condução da regeneração natural”.

- A Resolução coíbe a pesquisa científica: A pesquisa científica é livre de qualquer vínculo com a Resolução e, quando isso é feito, se deve exclusivamente à interpretação equivocada de seu conteúdo. Nesse caso, ressalta-se ainda mais a necessidade de conhecer o conteúdo da Resolução para que ela não seja aplicada indevidamente e se atribuam críticas indevidas á sua funcionalidade. Em seu Artigo 13º a Resolução justamente estabelece linhas prioritárias de pesquisa e capacitação em restauração ecológica para preencher as lacunas de conhecimento apontadas pelos participantes dos encontros de atualização da Resolução. Essas recomendações, muitas vezes, facilitam o financiamento de projetos científicos por entidades públicas de fomento à pesquisa.

\section{Considerações finais}

São Paulo é certamente o Estado onde mais se restauram florestas tropicais e subtropicais em larga escala no Brasil e provavelmente no mundo. Os erros e acertos nesse processo de consolidação da prática da restauração ecológica têm proporcionado aprendizados que culminaram na elaboração participativa de uma Resolução estadual orientativa para a restauração ecológica no Estado. Embora sempre haja oportunidades de melhoria em uma Resolução que ousa orientar uma atividade tecnológica tão complexa, a constante atualização e discussão pública em torno do tema deixam claro que o caminho mais correto a seguir é o aperfeiçoamento contínuo desse instrumento legal no lugar de simplesmente criticá-lo ou bani-lo, como propõem alguns atores sociais. Essa resolução é resultado de um compromisso público com uma restauração ecológica capaz de atingir seus objetivos maiores.

Outras estratégias de mitigação dos impactos decorrentes da degradação ambiental, tal como sistemas agroflorestais e reflorestamentos com espécies exóticas, também têm seu valor para o restabelecimento dos serviços ambientais, mas essas estratégias devem ser tratadas em outra esfera conceitual que não a da 
restauração ecológica de florestas megadiversas, em que a manutenção dos serviços florestais, inclusive o de retenção da biodiversidade nativa, deve ser o objetivo norteador central.

Diante do exposto, conclui-se que a adoção de instrumentos legais estaduais orientadores das ações de restauração ecológica, logicamente respeitando-se o contexto de cada situação particular, pode servir como importante ferramenta de política pública ambiental e induzir a restauração de florestas com maiores chances de viabilidade biológica em médio e longo prazos.

\section{REFERÊNCIAS}

ALMEIDA-NETO, M. et al. Vertebrate dispersal syndromes along the Atlantic forest: broad-scale patterns and macroecological correlates. Global Ecology and Biogeography, v.17, n.4, p.503-513, 2008.

ARONSON, J.; DHILLION, S.; LE FLOC’H, E. On the need to select an ecosystem of reference, however imperfect: A reply to Pickett e Parker. Restoration Ecology, v.3, n.1, p.1-3, 1995.

ARONSON, J. et al. Are socioeconomic benefits of restoration adequately quantified? A metaanalysis of recent papers (2000-2008) in Restoration Ecology and 12 other scientific journals. Restoration Ecology, v.18, n.2, p.143-154, 2010.

BARBOSA, L. M. et al. Recuperação florestal com espécies nativas no estado de São Paulo: pesquisas apontam mudanças necessárias. Florestar Estatístico, v.6, n.1, p.28-34, 2003.

BARBOSA, L. M. et al. Diagnóstico sobre produção de sementes e mudas de espécies florestais nativas do estado de São Paulo. Informativo ABRATES, v.12, n. 2, p.527, 2009.

BASCOMPTE, J.; JORDANO, P.; OLESEN, J.M. Asymmetric coevolutionary networks facilitate biodiversity maintenance. Science, v.312, n.5772, p.431-433, 2006.

BAWA, K. S. Breeding systems of tree species of a lowland tropical community. Evolution, v.28, n.1, p.85-92, 1974.
BECKER, C. G. et al. Habitat split and the global decline of amphibians. Science, v.318, n.5857, p.1775-1777, 2009.

BELLOTTO, A. et al. Inserção de outras formas de vida no processo de restauração. In: RODRIGUES, R. R.; BRANCALION, P. H. S.; ISERnhAgen, I. (Orgs.) Pacto para a restauração ecológica da Mata Atlântica: referencial dos conceitos e ações de restauração florestal. São Paulo: Instituto BioAtlântica, 2009. p.55-61.

BERTONCINI, A. P.; RODRIGUES, R. R. Forest restoration in an indigenous land considering a forest remnant influence (Avaí, São Paulo State, Brazil). Forest Ecology and

Management, v.255, n.3-4, p.513-521, 2008.

BORGES, E. E. L.; LOPES, E. S.; SILVA, G. F. Avaliação de substâncias alelopáticas em vegetação de uma floresta secundária. 1- Árvores. Revista Árvore, v.17, n.1, p.69-84, 1993.

BRANCALION, P. H. S. et al. Plantio de árvores nativas brasileiras fundamentado na sucessão florestal. In: RODRIGUES, R. R.; BRANCALION, P. H. S.; ISERNHAGEN, I. (Orgs.) Pacto para a restauração ecológica da Mata

Atlântica: referencial dos conceitos e ações de restauração florestal. São Paulo: Instituto BioAtlântica, 2009a. p.14-23.

BRANCALION, P. H. S.; GABRIEL, V. A.; GÓMEZ, J. M. Do terrestrial tank bromeliads in Brazil create safe sites for palm establishment or act as natural traps for its dispersed seeds?

Biotropica, v.41, n.1, p.3-6, 2009.

CASTRO, C. C.; MARTINS, S. V.; RODRIGUES, $\mathrm{R}$. R. A focus on plant reproductive biology in the context of forest restoration. In: RODRIGUES, R. R.; MARTINS, S. V.; GANDOLFI, S. (Eds.). High diversity forest restoration in degraded áreas: methods and projects in Brazil. New York: Nova Science Publishers, 2007. p.197-206.

CHAZDON, R. L. et al. Beyond reserves: a research agenda for conserving biodiversity in human-modified tropical landscapes.

Biotropica, v.41, n.2, p.142-153, 2009.

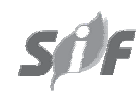

Revista Árvore, Viçosa-MG, v.34, n.3, p.455-470, 2010 
CLEWELL, A. F.; ARONSON, J. Ecological restoration: principles, values, and structure of an emerging profession. Washington: Island Press, 2007.

DURIGAN, G.; SIQUEIRA, M. F.; FRANCO, G. A. D. C. Threats to the Cerrado remnants of the state of São Paulo, Brazil. Scientia Agricola, v.64, n.4, p.355-363, 2007.

DYER, L. A. et al. Host specificity of Lepidoptera in tropical and temperate forests. Nature, v.448, p.696-700, 2007.

GANDOLFI, S.; JOLY, C. A.; RODRIGUES, R. R. Permeability - Impermeability: canopy trees as biodiversity filters. Scientia Agricola, v.64, n.4, p.433-438, 2007.

GRIME, J. P. Benefits of plant diversity to ecosystems: immediate, filter and founder effects. Ecology, v.86, n.6, p.902-910, 1997.

GUILLMAN, L. N.; OGDEN, J. Microsite heterogeneity in litterfall risk to seedlings. Austral Ecology, v.30, n.5, p.497-504, 2005.

HOWE, H. F.; SMALLWOOD, J. Ecology of seed dispersal. Annual Review of Ecology and Systematics, v.13, n.2, p.201-228, 1982.

\section{INSTITUTO BRASILEIRO DE GEOGRAFIA} ESTATÍSTICA - IBGE. 2006. Mapa de Biomas e de Vegetação. http:// www.ibge.gov.br/home/presidencia/noticias/ noticia_visualiza.php?id_noticia=169eid.

JONES, C. G.; LAWTON, J. H.; SHACHAK, M. Positive and negative effects of organisms as physical ecosystem engineers. Ecology, v.78, n.7, p.1946-1957, 1997.

JORDANO, P. et al. Ligando frugivoria e dispersão de sementes à biologia da conservação. In: ROCHA, C. F. D. et al. (Eds.) Biologia da conservação: essências. São Carlos: Rima, 2006. p.411-436.

KAGEYAMA, P. Y.; GANDARA, F. B. Recuperação de áreas ciliares. In: RODRIGUES, R. R.; LEITÃ̃O-FILHO, H. F. (Eds.). Matas ciliares: conservação e recuperação. São Paulo: EDUSP, 2004. p.249-269.
KEARNS, C. A.; INOUYE, D. W.; WASER, N. M. Endangered mutualisms: the conservation of plant-pollinator interactions. Annual Review of Ecology, Evolution, and Systematics, v.29, n.1, p.83-112, 1998.

KLINK, C. A.; MACHADO, R. B. Conservation of the brazilian cerrado. Conservation Biology, v.19, n.3, p.707-713, 2005.

LAMBAIS, M. R. et al. Bacterial diversity in tree canopies of the Atlantic Forest. Science, v.312, n.5782, p.1917, 2006.

LOREAU, M. et al. Biodiversity and ecosystem functioning: current knowledge and future challenges. Science, v.294, n.5543, p.804-808, 2001.

MELO, F. P. L.; DIRZO, R.; TABARELLI, M. Biased seed rain in forest edges: evidence from the Brazilian Atlantic forest. Biological Conservation, v.132, n.1, p.5060, 2006.

METZGER, J. P. Como restaurar a conectividade de paisagens fragmentadas? In: KAGEYAMA, P. Y. et al. (Orgs.). Restauração ecológica de ecossistemas naturais. Botucatu: FEPAF, 2003. p.51-76.

METZGER, J. P. Conservation issues in the Brazilian Atlantic forest. Biological

Conservation, v.142, n.6, p.1138-1140, 2009.

METZGER, J. P. O Código Florestal tem base científica? Conservação e Natureza, v.8, n.1, 2010 (no prelo).

MITCHELL, R. J. et al. The ecological engineering impact of a single tree species on the soil microbial community. Ecology, v.98, n.1, p.50-61, 2010.

MITTERMEIER, R. A. et al. (Eds.). Hotspots revisited: Earth's biologically richest and most endangered terrestrial ecoregions. Washington: Cemex, 2004. 390p.

MODNA, D.; DURIGAN, G.; VITAL, M. V. C. Pinus elliottii Engelm como facilitadora da regeneração natural da mata ciliar em região de Cerrado, Assis, SP, Brasil. Scientia

Forestalis, v.38, n.85, p.73-83, 2010. 
MOLOFSKY, J.; AUGSPURGER, C. K. The effect of leaf litter on early seedling establishment in a tropical forest. Ecology, v.73, n.1, p.68-77, 1992.

MONTAGNINI, F.; SANCHO, F. Impacts of native trees on tropical soils: a study in the Atlantic lowlands of Costa Rica. Ambio, v.19, n.8, p.386390, 1990.

MONTGOMERY, R. A.; CHAZDON, R. L. Forest structure, canopy architecture, and light transmittance in tropical wet forests. Ecology, v.82, n.10, p.2707-2718, 2001.

MUÑOZ, A. A. et al. Diversity and host tree preference of vascular epiphytes and vines in a temperate rainforest in southern Chile.

Australian Journal of Botany, v.51, n.1, p.1-11, 2003.

MYERS, N. et al. Biodiversity hotspots for conservation priorities. Nature, v.403, p.853-858, 2000.

NICOTRA, A. B.; CHAZDON, R. L.; IRIARTE, S. V. B. Spatial heterogeneity of light and woody seedlings regeneration in tropical wet forests. Ecology, v.80, n.6, p.1908-1926, 1999.

\section{PARCELAS PERMANENTES/BIOTA/FAPESP.} 2006a. IV Relatório Temático do Projeto Parcelas Permanentes - Parte III: A vegetação. http://www.lerf.esalq.usp.br/ parrel2005.php; Acesso em 10.XI.2007a.

REY BENAYAS, J. M. et al. Enhancement of biodiversity and ecosystems services by ecological restoration: a meta-analysis. Science, v.325, n.5944, p.1121-1124, 2009.

RIBEIRO, M. C. et al. The Brazilian Atlantic Forest: How much is left, and how is the remaining forest distributed? Implications for conservation. Biological Conservation, v.142, n.6, p.1141-1153, 2009.

RODRIGUES, R. R.; BONONI, V. L. R. (Orgs.) Diretrizes para a conservação e restauração da biodiversidade no estado de São Paulo. São Paulo: Instituto de Botânica/Programa BIOTA/FAPESP, 2008.
RODRIGUES, R. R.; BRANCALION, P. H. S.; ISERNHAGEN, I. (Orgs.) Pacto para a restauração ecológica da Mata Atlântica: referencial dos conceitos e ações de restauração florestal. São Paulo: Instituto BioAtlântica, 2009a.

RODRIGUES, R. R. et al. On the restoration of high diversity forests: 30 years of experiences in the Brazilian Atlantic Forest. Biological Conservation, v.142, n.6, p.1242-1251, 2009 b.

RODRIGUES, R.R. et al. Large-scale ecological restoration of high diversity tropical forests in SE Brazil. Forest Ecology and Management, (no prelo) 2010.

SÃO PAULO. Secretaria de Meio Ambiente do Estado de São Paulo. Resolução nº68/2008, de 19 de setembro de 2008. Diário Oficial do Estado de São Paulo, São Paulo, 20/09/2008. Seção Meio Ambiente, 2008a.

SÃO PAULO. Secretaria de Meio Ambiente do Estado de São Paulo. Resolução n ${ }^{4} 4 / 2008$, de 30 de junho de 2008. Diário Oficial do Estado de São Paulo, São Paulo, 02/07/2008. Seção Meio Ambiente, 2008b.

SÃO PAULO. Secretaria de Meio Ambiente do Estado de São Paulo. Resolução nº8/2007, de 7 de março de 2007. Diário Oficial do Estado de São Paulo, São Paulo, 08/03/2007. Seção Meio Ambiente, 2007.

SEIDLER, T. G.; PLOTKIN, J. B. Seed dispersal and spatial pattern in tropical trees. PLOS Biology, v.4, n.1, p.1-6, 2006.

SERI - Society for Ecological Restoration International e Policy Working Group. The SER International Primer on Ecological Restoration. www.ser.org e Tucson: Society for Ecological Restoration International, 2004.

SILVA, J. M. C.; TABARELLI, M. Tree species impoverishment and the future flora of the Atlantic forest of northeast Brazil. Nature, v.404, n.6773, p.72-74, 2000.

SILVA, W. R. A importância das interações plantaanimal nos processos de restauração. In:

KAGEYAMA, P. Y. et al. (Orgs.) Restauração ecológica de ecossistemas naturais. Botucatu: FEPAF, 2003. p.77-90.

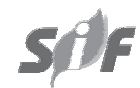

Revista Árvore, Viçosa-MG, v.34, n.3, p.455-470, 2010 
SIQUEIRA FILHO, J. A.; TABARELLI, M. Bromeliad species from the Atlantic forest of north-east Brazil: losses of critical populations of endemic species. Oryx: Journal of Fauna and Flora International, v.40, n.2, p.218-224, 2006.

SOUZA, F. M.; BATISTA, J. L. F. Restoration of seasonal semideciduous forests in Brazil: Influence of age and restoration design on forest structure. Forest Ecology and Management, v.191, n.1-3, p.185-200, 2004.

TABARELLI, M. et al. Challenges and opportunities for biodiversity conservation in the Brazilian Atlantic Forest. Conservation Biology, v.19, n.3, p.695-700, 2005.

TABARELLI, M.; LOPES, A. V. F.; PERES, C. Edge-effects drive tropical forest fragments towards an early-successional system. Biotropica, v.40, n.6, p.657-661, 2008.
TABARELLI, M. et al. Prospects for biodiversity conservation in the Atlantic Forest: lessons from aging human-modified landscapes. Biological Conservation, 2010 (no prelo).

VÁZQUEZ-YANEZ, C. et al. Light beneath the litter in a tropical forest: effect on seed germination. Ecology, v.75, n.1, p.1952-1958, 1990.

ZIMMERMAN, J. K.; OLMSTED, I. C. Host tree utilization by vascular epiphytes in a seasonally inundated forest (Tintal) in Mexico. Biotropica, v.24, n.3, p.402-407, 1992.

ZINKE, P. J. The pattern on influence of individual forest trees on soil properties. Ecology, v.43, n.1, p.130-133, 1962.

WRIGHT, J. et al. Restoring biodiversity and ecosystem function: will an integrated approach improve results? In: NAEEM, S. et al. (Eds.). Biodiversity, ecosystem functioning and human wellbeing. Oxford: Oxford University Press, 2009. p.167-177. 